\title{
COVID-19 and endocrine and metabolic diseases. An updated statement from the European Society of Endocrinology
}

\author{
M. Puig-Domingo ${ }^{1}$ M. Marazuela ${ }^{2}$ B. O. Yildiz ${ }^{3}$ A. Giustina $\mathbb{D}^{4}$ \\ Received: 31 March 2021 / Accepted: 16 April 2021 / Published online: 8 May 2021 \\ (C) The Author(s), under exclusive licence to Springer Science+Business Media, LLC, part of Springer Nature 2021
}

\begin{abstract}
Background COVID-19 has completely changed our daily clinical practice as well as our social relations. Many organs and biological systems are involved in SARS-Cov-2 infection, either due to direct virus-induced damage or to indirect effects that can have systemic consequences. Endocrine system is not only an exception but its involvement in COVID-19 is so relevant that an "endocrine phenotype" of COVID-19 has progressively acquired clinical relevance.

Aim We have been appointed by the European Society of Endocrinology (ESE) to update with the current statement ESE members and the whole endocrine community on the emerging endocrine phenotype of COVID-19 and its implication for the prevention and management of the disease.

Conclusions Diabetes has a major role in this phenotype since it is one of the most frequent comorbidities associated with severity and mortality of COVID-19. Careful management including treatment modifications may be required for protecting our patients rather with known diabetes from the most dangerous consequences of COVID-19 or hospitalized with COVID19 , but also in patients with SARS-CoV-2 induced newly onset diabetes. Obesity increases susceptibility to SARS-CoV-2 and the risk for COVID-19 adverse outcome. Adequate nutritional management needs to be granted to patients with obesity or undernourishment in order to limit their increased susceptibility and severity of COVID-19 infection. Lack of vitamin D, hypocalcemia and vertebral fractures have also emerged as frequent findings in the hospitalized COVID-19 population and may negatively impact on the outcome of such patients. Also, in patients with adrenal insufficiency prompt adaptation of glucocorticoid doses may be needed. Moreover, in this updated statement role of sex hormones as well as peculiar pituitary and thyroid aspects of COVID-19 have been included. Finally, in view of the mass vaccination, potential implications for endocrine patients should be considered.
\end{abstract}

Keywords Covid19 $\cdot$ Diabetes mellitus $\cdot$ Obesity $\cdot$ Vitamin D $\cdot$ Pituitary $\cdot$ Thyroid

A. Giustina

giustina.andrea@hsr.it

1 Endocrinology and Nutrition Service, Department of Medicine, Germans Trias i Pujol Health Science Research Institute and Hospital, Universitat Autònoma de Barcelona, Badalona, Spain

2 Department of Endocrinology, Hospital Universitario de la Princesa, Instituto de Investigación de la Princesa, Universidad Autónoma de Madrid, Madrid, Spain

3 Division of Endocrinology and Metabolism, Department of Internal Medicine, Hacettepe University School of Medicine, Hacettepe Ankara, Turkey

4 Institute of Endocrine and Metabolic Sciences, Vita-Salute San Raffaele University, IRCCS San Raffaele Hospital, Milano, Italy

\section{Introduction}

COVID-19 initially defined as a potentially severe respiratory syndrome caused by severe acute respiratory syndrome coronavirus 2 (SARS-CoV-2) progressively demonstrated to be a systemic disease with relevant extrapulmonary manifestations which increase the lethality of COVID-19 and mainly include vascular, cardiac, kidney, gastrointestinal, and central nervous system complications [1]. Pathophysiologically, ubiquitous expression of angiotensin-converting enzyme 2 (ACE2), the receptor which is responsible for the entry of SARS-CoV-2 at the cellular level [2], widespread endothelial damage, and altered immune response contribute to the multiple organ involvement in COVID-19 [3].

During the persisting Coronavirus disease 2019 (COVID-19) outbreak (we are facing the "third wave" of the pandemic) endocrinologists from all over Europe 
discovered themselves to be crucial in the fight against the COVID-19. In fact, they moved first with self-sacrifice and decision to the first line of care of affected patients, in collaboration with other physicians such as those in internal medicine and emergency units, but also greatly contributed to the profiling of an endocrine phenotype of COVID-19. In fact, in the evolving knowledge about COVID-19 a major endocrine and metabolic involvement has been progressively better understood with many endocrine organs, tissues, and molecules being directly or indirectly affected or negatively influencing outcomes of COVID-19 [4, 5].

A well-defined endocrine phenotype can be of help in preserving the health status and prevent adverse COVID-19 outcomes in both the general population and in people affected by different endocrine diseases. People with diabetes in particular are at high-risk of severe COVID-19 if infected by SARS-Cov-2, which can also affect directly beta-cell function. Moreover, other endocrine diseases such as obesity, hypovitaminosis D and adrenal dysfunctions may impact on susceptibility and severity of COVID-19 $[6,7]$. Therefore, due to the relevant involvement and increased responsibility of endocrinologists worldwide in the persisting COVID-19 pandemic, as well as to the rapidly evolving knowledge on this new disease and its consequences, we have been appointed by the European Society of Endocrinology (ESE) to write an update of our previously published statement [4] in order to continue to support the ESE members and the whole endocrine community in this critical situation.

\section{COVID-19 and diabetes mellitus}

\section{Diabetes mellitus and the risk of SARS-CoV-2 infection}

Subjects with diabetes mellitus may be at increased risk for infectious diseases which can be decreased, although not completely abolished, by appropriate glycemic control. In this context, all people with diabetes (over the age of 2) are recommended influenza vaccinations [8]. A rapidly increasing amount of published data on the incidence of COVID-19 in patients with diabetes has accumulated over the last year clearly indicating that diabetes and obesity are predictors of worse outcomes and mortality [9-13].

\section{Increased risk of morbidity and mortality in patients with diabetes and COVID-19}

The largest study performed in Catalonia including data of 118,150 COVID-19 patients, found a diabetes prevalence of $9.3 \%$ in the COVID-19 affected population [14]. In this cohort, $14.8 \%$ required hospitalization in the first month after COVID-19 detection. Data on the presence of diabetes in COVID-19 patients requiring hospitalization is very variable among different countries; in this regard China reported $7.3 \%$ [15], while in South Korea it was $17.9 \%$ and $43.3 \%$ in US veterans [16].

Critically ill patients affected by COVID-19 are older and have more previous co-morbidities, mostly of cardiovascular and metabolic nature, compared to non-ICU patients [17]. The most frequent phenotype of a COVID-19 patient requiring hospitalization is an aged one (60-70 years) in which the presence of metabolic co-morbidities included hypertension (between 30 and 55\%), diabetes mellitus (between 15 and $33 \%$ ), obesity (20-40\%), coronary heart diseases $(5.8 \%)$, and cerebrovascular disease $(2.3 \%)$ is very frequent. This is relatively consistent in western countries while in Chinese series this metabolic phenotype is less frequently reported and age is lower than in European and American reports [18].

In a large UK cohort of people dying of COVID-19 in the hospital, $32 \%$ had type 2 diabetes and $1.5 \%$ type 1 diabetes, and among people with diabetes, male sex, older age, renal impairment, non-white ethnicity, socioeconomic deprivation, previous stroke, and heart failure were associated with increased COVID-19-related mortality in both type 1 and type 2 diabetes [19]. Diabetes was also associated with longer hospital stay and the necessity of assisted ventilation and ICU admittance [20].

We now know that mortality in either type 1 or type 2 diabetes has consistently increased during the year of pandemic, and these diabetic populations died not only because of the presence of the aforementioned co-existing co-morbidities but also due to the fact that glycemic control has been recognized as an associated factor to fatality. Thus, mortality in diabetic persons infected with SARS-CoV-2 is also related to prior metabolic control, (see below) [21].

Interestingly, use of current antihypertensive drugs included in diabetes treatment, and particularly ACE inhibitors, was not associated with increased mortality [22]. Moreover, the good news is that the use of statins confers certain degree of protection toward mortality, and therefore, it is recommended not to withdraw them even when the patient is hospitalized [23]. A retrospective study performed in Italy indicated that the use of sitagliptin was also associated to a reduced mortality during hospitalization [24]. All these findings will require to be confirmed in the months to come with more data.

In summary, according to current evidence, people with diabetes may be at increased risk for SARS-CoV-2 infection, and they are at high risk of medical complications including death. Accordingly, in these patients, active vigilance and testing in outpatient endocrine clinics, as well as early hospitalization for COVID-19 is recommended [4]. 


\section{Importance of glycemic control in those with COVID-19 and diabetes}

While the restoration of normoglycemia seems to be related to a better prognosis for bacterial infections, in viral disease and especially in COVID-19 diabetic patients, the impact of antihyperglycemic treatments on the outcomes is still under evaluation [25].

In vitro glucose exposure of pulmonary epithelial cells significantly increases influenza virus infection and replication and elevated glucose levels impair the antiviral immune response. In viral disease animal models, diabetes is associated with numerous lung structural changes, including augmented permeability of the vasculature and a collapsed alveolar epithelium [26]. Hyperglycemia may also affect pulmonary function [27, 28], and respiratory dysfunction induced by COVID-19 is exacerbated in patients with diabetes. In fact, COVID-19 pneumonia radiologic scores are worse in diabetic patients [29].

Recently published data indicate that glycemic control is related to outcomes. Thus, the last A1c previous to the development of COVID-19 has been reported to show a linear relationship to outcomes and particularly to mortality when A1c is $>10 \%$ [19]; these latter figures equally applied to either type 2 and also type 1 diabetes. Conversely, low A1c has also been related to mortality in type 2 diabetes while the relationship is not statistically significant for type 1 diabetes. Glycemic factors combined with obesity amplify the deleterious effects upon mortality and severe outcomes, impacting also individuals $<70$ years apart from those $>80$ years; this latter fact is particularly relevant in Asian and black ethnicities [19].

Besides the importance of the A1c previous to SARSCoV-2 infection, glycemic control and glycemic fluctuations during the first days of hospital stay have additionally been reported as important determinants of hospital length stay, ICU requirement, and mortality with odds ratios ranging from 1.97 and 2.73 in Wuhan patients [30]. Moreover, the strength of the association of these outcomes was higher if the patients received corticosteroid treatment, thus requiring intensive insulin treatment.

Different factors are influenced by hyperglycemia and play an important role regarding tissue damage in these patients, such as glucose-dependent impaired pulmonary function, exaggerated inflammasome response, reninangiotensin system dysregulation, aberrant protein glycation including dysfunction of immunoglobulins and ACE2, increased coagulation activity, potential bacterial superinfection and, as commented below, direct pancreatic damage.

Interestingly, it has been reported that treatment with metformin and statins are associated with lower disease severity and mortality, suggesting that these treatments should not be stopped at the time of admittance in the hospital due to COVID-19 pneumonia [31].

\section{COVID-19 and newly onset diabetes}

Diabetes is not only one of the most frequent co-morbidities of hospitalized patients with severe COVID-19 but it has progressively emerged that a bidirectional relationship between diabetes and COVID-19 may exist [32]. In fact, since pancreatic $\beta$-cells abundantly express ACE2 receptor, they may be damaged by SARS-CoV-2 with consequent worsening of hyperglycemia in patients with known diabetes, often complicated by ketoacidosis or hyperosmolarity with high-dose insulin requirements. Moreover, also new onset of diabetes in COVID-19 patients previously nondiabetic has been consistently reported [32], disclosing a potential diabetogenic action of SARS-CoV-2 [33]. The transient or persistent nature of this hyperglycemia in COVID-19 as well as the true incidence and characterization of this newly onset diabetes are still not entirely known and international registry efforts are ongoing in order to collect and analyze those cases worldwide [32].

\section{Diabetic retinopathy}

Microvascular diabetic damage including severe retinopathy and/or nephropathy and/or diabetic foot predicted adverse outcomes in COVID-19 patients [34]. Interestingly, in a cross-sectional study on 187 hospitalized patients with poorly controlled diabetes and COVID-19, the presence of retinopathy was independently associated with intubation (OR slightly lower than 6). Although due to the type of study, the mechanistic association could not be established, it can be speculated that diabetic microangiopathy may be surrogate marker of endothelial dysfunction/ damage representing a risk factor for severe COVID-19 tissue damage [35].

\section{Treatment of people with diabetes infected by SARS-CoV-2}

People with diabetes who are infected with SARS-CoV-2 may experience a worsening of glycemic control during the course of the disease, as it occurs with other infectious episodes. Implementation of "sick day rules" is therefore necessary to avoid possible decompensation of diabetes. Patients with type 1 diabetes should increase frequency of blood glucose and urinary ketones measurement in case of fever and hyperglycemia also proactively modify basal insulin dose or using correctional bolus in order to maintain euglycemia and avoid worsening of glycemic control [4]. Also, patients under oral hypoglycemic agents may need more frequent glycemic monitoring and modifications in 
drug doses. If patients on sodium-glucose cotransporter-2 inhibitors are hospitalized, treatment needs to be stopped, due to a potentially higher risk of ketoacidosis development [36]. Since recent data seem to indicate the protective effect apparently associated with metformin, DPP4, as well as statins, if there are no specific contraindications, continuing on these oral compounds may be of benefit for these patients.

Insulin is the most efficacious agent for the control of hyperglycemia in hospitalized seriously sick patients and is also the case for COVID-19 infection [4]. In those patients treated with dexamethasone, insulin requirements are particularly high and use to be in the range of 1.2-1.5 units $/ \mathrm{kg}$. This dosage should be implemented at the time of initiation of corticosteroids to prevent delay in glycemic control.

In the case of symptomatic COVID-19 without pneumonia, if the clinical decision is to follow the patient in a non-hospital environment, current antidiabetic treatment could be maintained provided that close vigilance on possible metabolic deterioration is performed.

\section{COVID-19 and other endocrine and metabolic disorders}

\section{Obesity}

\section{Impact of obesity on clinical outcome of patients with COVID-19}

Limited data are available regarding susceptibility to SARS$\mathrm{CoV}-2$ in patients with obesity whereas there are several reports assessing the burden of obesity on the clinical course of COVID-19. Most of the earlier studies on COVID-19 did not provide information on body mass index (BMI) or other measures of obesity whereas others reported conflicting results with similar, lower or higher rates of obesity compared to the general population. A recent analysis of over 100.000 individuals with an outpatient diagnosis of COVID-19 in Catalonia, Spain reported a hazard ratio of $1.23(1.21-1.25)$ for obesity suggesting that individuals with obesity are at increased risk to be infected with SARS-CoV-2 [37]. In a recent meta-analysis of 19 fair to good quality studies reporting on obesity and at least two different outcomes, the pooled obesity prevalence rates were $32 \%$ in hospitalized patients, $41 \%$ in patients admitted to intensive care unit (ICU), $43 \%$ in patients needing invasive mechanical ventilation (IMV), and 33\% in those who died [38]. It is important to note that the local obesity prevalence in the background population varies by geographical region and might influence the results in patients with COVID-19.

A comparative risk assessment model of over 900,000 COVID-19 hospitalizations in the US showed that $63.5 \%$ were attributable to cardiometabolic conditions and the top risk factor was obesity accounting for $30.2 \%$. The proportion of COVID-19 hospitalizations attributable to obesity (BMI:30-40 kg/m²) was similar for the age groups of 18-49 years and $\geq 65$ years whereas severe obesity was a higher risk for hospitalization in the youngest age groups (13.5\% versus $9.3 \%$ ), and in women compared to men $(13.8 \%$ versus $9.2 \%$ ) [39]. Using various inclusion criteria and definitions for the outcome variables, meta-analyses reported increased risk of severe disease and composite poor outcome in patients with COVID-19 and obesity with odds ratios varying between 1.39 and 2.35 [38]. In general, available studies consistently indicate increased risk for disease severity including hospitalization, ICU admission, and IMV need. However, data on mortality are conflicting. For example, American Heart Association's COVID-19 Cardiovascular Disease Registry data of 7606 patients with $17 \%$ mortality ratio showed that severe obesity was associated with increased risk of in hospital death (hazard ratio, 1.26 [95\% CI, 1.00-1.58]), particularly in those younger than 50 years [40]. In the UK Biobank study of over 500,000 individuals where 410 patients died due to COVID-19, hazard ratios for women and men were 2.21 $(1.69 ; 2.88)$ and $1.78(1.44 ; 2.21)$ respectively [41]. In contrast, other studies have failed to show excess mortality associated with obesity in COVID-19 patients [42, 43]. Similar to individual studies, there is a discrepancy in mortality results of meta-analyses. Some report increased risk of mortality with odds ratios varying between 1.37 and 3.68 , whereas others fail to confirm this finding with odds ratios of 1.05-1.28 [38]. The differences in study populations and degree of obesity, healthcare systems, testing strategies, indications for hospitalization, ICU admission, or IMV might have contributed to the discrepancies of mortality data. Whether obesity survival paradox is relevant particularly for COVID-19 patients with mild obesity remains to be determined [44].

\section{Potential mechanisms linking obesity and poor outcome in COVID-19}

It is well known that obesity, particularly in the severe form, is commonly associated with pulmonary dysfunction which might predispose patients to develop respiratory failure in the case of pneumonia. Most patients with obesity have co-morbidities including type 2 diabetes, hypertension, cardiovascular disease, and kidney disease which could adversely affect the clinical outcome of COVID-19. Additionally, several mechanisms have been proposed about the association between obesity and poor COVID-19 outcomes. Higher expression of ACE2 in adipose tissue may lead to prolonged viral shedding and exposure in patients with obesity, increasing the susceptibility to 
SARS-CoV-2 infection and the risk of disease aggravation [45, 46]. Obesity-driven chronic inflammation, aberrant cytokine activation, decreased adiponectin and increased leptin secretions, and dysfunction of innate and adaptive immunity may contribute to worse clinical outcomes in patients with COVID-19. Obesity is also associated with pulmonary dysfunction, hypercoagulability and increased risk of thrombosis, which has emerged as an important factor leading to a more severe clinical course in COVID19 patients [47]. Future studies are needed to determine whether these plausible mechanisms are actually linked to COVID-19 outcomes.

\section{Recommendations for people with obesity regarding SARS- CoV-2 infection}

Considering available data consistently suggesting that obesity increases the risk of poor outcome for COVID-19, measurement of anthropometric parameters should be routinely performed in patients tested positive for SARS-CoV2 as a part of risk assessment. Patients with obesity and COVID-19 should be considered as a higher risk population. Increased vigilance, priority on detection and testing, close monitoring, and earlier intensive treatment should be considered in these patients to avoid unfavorable clinical outcomes. It is critical that patients with obesity take all the possible precautions to avoid infection. Weight management, blood pressure, and blood glucose control have always been important to improve cardiometabolic health and prevent severe health consequences in obesity, but the risk of severe COVID-19 is now another important reason to focus on these issues.

It should be considered that persons with obesity who become ill and require hospitalization present challenges in the management. These include difficulties in venous access, position, transport and airway management, diagnostic imaging problems due to weight limitations of imaging machines, and the limited number of bariatric beds in hospitals. Healthcare systems in general are not yet well set up to manage an increasing number of patients with obesity in intensive care units and the current crisis highlighted their limitations even more.

Special attention to obesity is also important in the aspect of disease prevention. Lockdowns, travel and mobility restrictions and personal social isolation measures have been introduced in many countries to reduce the spread of SARS-CoV-2. These measures could result in lifestyle changes that can adversely affect chronic health conditions and increase the susceptibility for weight gain in the long term for people with normal weight and obesity. Dietary habits, physical activity, stress, and sleep characteristics could all play a role in weight gain. Social isolation associated with biological, behavioral and emotional alterations might eventually increase the number of individuals who will likely have a more severe course when infected with COVID-19. Thus, people with obesity should be encouraged to increase physical activity and gain healthy eating habits, develop strategies to reduce stress and optimize sleep during pandemic.

\section{COVID-19 and its nutritional consequences}

COVID-19 may be frequently accompanied by anosmia and gastrointestinal disturbances like nausea, vomiting, and diarrhea that affect both, food intake and absorption [1]. These symptoms have been directly related to mucosal invasion by the virus and by viral particles. According to the classification of the European Society for Clinical Nutrition and Metabolism (ESPEN) guidelines and other scientific societies [48, 49], acute Disease Related Malnutrition (DRM) may account for different reasons, but mainly because of increased energy requirements related to severe inflammation with difficulty to achieve them due to hyporexia and coexistence of eating difficulties [49]. This definition of DRM fits perfectly with what clinicians have seen in COVID-19 patients. In COVID-19, loss of muscle mass and functionality due to the catabolic state caused by the viral infection is present and directly related to disease severity. Additionally, immobilization and prolonged hospital stay, aggravates this situation, particularly in those patients requiring ICU admission. As age is the most relevant determining factor for disease severity and mortality, it is concordant that many of these patients have a high risk of malnutrition due to previous ongoing chronic diseases or just aging condition before hospital admission, which itself is associated with adverse changes in body composition, such as the gradual loss of skeletal muscle mass and impaired muscle function (sarcopenia) [50, 51]. Few studies, performed mostly in the Chinese population, have evaluated nutritional status in COVID-19 patients, finding a risk of malnutrition in $\sim 80 \%$ of them during hospitalization $[52,53]$. In about $15 \%$ of patients, artificial nutritional support is required for hospitalized cases, in particular those with the more severe conditions and those showing high inflammosome profile, and ICU admittance [54].

Anorexia is probably the most prevalent symptom in the early phase of the clinical disease, also in milder forms, and it uses to persist in about $80 \%$ of cases for about at least 2 more weeks. Patients describe even aversion to food. During the healing period, a rebound hyperorectic state occurs in the majority of cases. Consequently, weight loss is a common feature and even in mild cases $3-5 \mathrm{~kg}$ of weight may be lost. Subjects may then recover or even to be recovered or even gain more weight in the weeks after, in parallel with hyperphagia [54]. The intensity of anorexia 
and its rapid disappearance in the recovery phase clearly suggests that not just the infective catabolic disease state with high circulating concentrations of cytokines plays a role. ACE2 has also been found to be expressed in the human hypothalamus and a case report confirmed viral invasion and replication in the hypothalamus in a postmortem patient brain [55]. Thus, it has been speculated that viral infiltration at the hypothalamic level may participate in this phenomenon and the virus clearance from the hypothalamus would contribute to hyperphagia. The disorectic situation may, however, last even for 6 months in about $10 \%$ of the patients [54].

For those cases requiring admittance to the hospital, full nutritional status evaluation during the first days is required for detection of potential sarcopenia in apparently frail patients, and prevention of excessive weight loss. Weight loss in severe cases accounts predominantly for muscle mass, while in the recovery phase in which weight regain takes place, it consists mostly in adipose tissue gains. Thus, the net metabolic balance regarding body composition in these patients is negative as their metabolic condition worsened.

In order to prevent sarcopenia development, high protein content diet with at least $1.5 \mathrm{mg} / \mathrm{kg}$ of body weight is recommended [48, 49]. Additional nutritional support with oral supplements or even tube feeding should be implemented earlier, according to the patient's diet intake. In those more severe cases requiring ICU admittance, oral nutrition supplements or parenteral nutrition should be started according to clinical judgment. During long hospital stays, a passive muscle rehabilitation program is also necessary to prevent muscle mass atrophy.

At hospital discharge, both a normocaloric high protein content diet for about 8 weeks, aiming to recover muscle lost and preventing excessive adipose tissue regain, as well as a personalized muscle exercise program are highly recommended.

\section{Bone and mineral metabolism in COVID-19}

\section{Hypocalcemia}

Hypocalcemia has become a major biochemical feature of COVID-19 after being initially reported in a previously thyroidectomized patient hospitalized with COVID-19 presenting with particularly low calcium levels possibly linked to subclinical hypoparathyroidism [56]. In fact, according to our series of more than 500 COVID-19 patients, hypocalcemia is highly prevalent [57], associated with inflammatory parameters and independently predicted the need for hospitalization [52]. Subsequently, it has also been shown that hypocalcemia may be a distinctive feature of COVID-19 since it is more frequently found in COVID-19 vs. non-COVID-19 patients hospitalized with acute respiratory disease [58].

Several studies have confirmed that calcium levels are lower in patients tested positive to SARS-CoV-2 RT-qPCR vs. negative patients and that hypocalcemia is independently associated with negative outcomes including ICU admission and mortality [59-61].

From a pathophysiological perspective, calcium plays a key role in the action of different enveloped viruses [62] and hypocalcemia has already been reported in patients with SARS [63]. Moreover, widespread lack of vitamin D (see below) may contribute relevantly to the high frequency with which hypocalcemia is found [64].

Since hypocalcemia occurring in COVID-19 may be severe and potentially life threatening, all patients with postsurgical hypoparathyroidism should be monitored carefully and never discontinue or down titrate their treatment (e.g., for side effects) prior to consulting their endocrinologist [65]. Moreover, patients with mild hypoparathyroidism not on chronic treatment, and particularly those overweight or obese should be carefully monitored in areas with high prevalence of COVID-19 and eventually adequately treated to prevent acute hypocalcemia [61, 66]. Finally, since hypocalcemia may negatively impact on cardiac and neurologic outcomes [56], calcium evaluation and monitoring in all patients admitted to the hospital with COVID-19 is recommended.

\section{Vitamin D}

Mediterranean countries, as Italy and Spain, are affected by the high prevalence of hypovitaminosis $\mathrm{D}$ as a consequence of a change in lifestyle and lack of food fortification with vitamin D at odds with Northern European countries (the Scandinavian paradox) [67]. Several authors evidenced an association between COVID-19 prevalence and its severity with latitude and related sunlight exposure [68, 69]. Moreover, home confinement particularly of elderly subjects may contribute to the worsening of the vitamin $D$ status in countries with widespread vitamin D deficiency [70]. Finally, it has been suggested that low vitamin D may negatively influence the outcome of patients admitted to ICU in whom vitamin D supplementation could reduce morbidity and mortality [71].

Hypovitaminosis D may expose to a high risk of COVID-19 and severe disease since it has been reported to predispose to systemic infections impairing immune responses [72] with the potential preventive role of vitamin D supplementation towards respiratory infections [73]. The specific role of vitamin D in COVID-19 may be due to ACE2 downregulation and its ability to counteract the cytokine storm characteristic in severe COVID-19 cases by modulating pro-inflammatory cytokines and regulating T-cell differentiation into Th2 phenotype [74]. 
Low levels of vitamin D adjusted for confounding factors have been found in different studies from different geographical areas in a considerable proportion of hospitalized COVID-19 patients with average levels lower than the general population [75]. Poor vitamin D status has also been reported in the majority of the studies to predict disease severity including chest CT stage and mortality risk [69], is also associated with severe endocrine co-morbidities of COVID-19 [76, 77].

In a Spanish pilot clinical trial, COVID-19 hospitalized patients with pneumonia were randomly assigned to standard of care combined or not with calcifediol, and this latter significantly reduced the requirement of ICU admission with no deaths [78].

Based on the above, we recommend that granting adequate vitamin D levels in the general population but particularly in high risk (elderly with diabetes and obesity) should be a good clinical practice. Supplementation with vitamin D of elderly co-morbid persons at high risk of coexistent COVID-19 and hypovitaminosis D is suggested [79].

\section{Vertebral fractures (VFs)}

Recently, it was reported a high prevalence (36\%) of morphometric VFs on lateral chest $\mathrm{X}$ rays in a single-center cross-sectional study, reaching the level of the most frequent co-morbidities in the COVID-19 population [75]. In particular, VFs did have a strong prognostic impact with a double mortality rate in patients with versus without VFs. Moreover, the mortality rate was significantly higher in patients bearing severe vs. mild and moderate VFs. Also, fractured patients are older, need more frequent hospitalization and mechanical ventilation vs. non-fracture patients [80].

The presence of VFs in COVID-19 could negatively influence respiratory function and increase the risk of pneumonia representing a marker of frailty and negative outcome [80]. Therefore, anti-osteoporotic treatment should not be discontinued even with the monoclonal antibody denosumab, which has been previously associated with increased risk of infections but apparently not of COVID-19 [81]. Finally, when lateral chest X-rays are performed in COVID-19 patients at hospital admission, we suggest that thoracic VFs should be searched for and reported for more comprehensive profiling of the risk of severe disease.

\section{Adrenals and pituitary and COVID-19}

\section{Adrenal insufficiency}

Regarding cortisol dynamics, autopsy studies performed on patients who died from SARS-CoV-1 have found degeneration and necrosis in the adrenal cortical cells, pointing to a direct cytopathic effect of the virus. Hence, it is likely that cortisol dynamics may also be altered in patients with SARSCoV-2 as ACE receptors have been reported in the adrenal cortical cells [82]. An acute adrenal insufficiency caused by a thrombotic event at the adrenal has also been reported [83].

In addition, certain amino acid sequences in the SARSCoV-1 are molecular mimics of the adrenocorticotropic hormone (ACTH). This could blunt the stress-induced cortisol rise, as antibodies produced against the viral particles will inadvertently decrease the circulating ACTH [84]. However, it is not yet known whether SARS-CoV-2 might be employing this same strategy as SARS-CoV-1. In addition, critical-illness related corticosteroid insufficiency related to COVID-19 can appear. This is a rare condition of relative adrenal insufficiency resulting from inadequate glucocorticoid-mediated anti-inflammatory activity in relation to the severity of stress caused by a critical illness [85].

It has been hypothesized that patients with adrenal insufficiency may be at increased risk of SARS-CoV-2 infection since they have an impaired natural immunity with neutrophil and natural killer-cell defective function [86]. Moreover, in patients with adrenal insufficiency, there could be a higher risk of an adrenal crisis after the infection [87]. However, in a recent survey of more than 200 Italian patients with primary or secondary adrenal insufficiency on regular follow-up and adequately trained, similar incidence of symptoms potentially related to SARS-CoV-2 infection as well COVID-19 severity as compared to controls were reported [88].

\section{Recommendations for patients with adrenal insufficiency}

Replacement treatment in hypoadrenalism is a challenge for clinicians and patients, since mimicking physiological serum cortisol fluctuations [89] in the absence of reliable biomarkers for appropriateness, is not easy to achieve [90]. Furthermore, many organic and/or functional factors might influence cortisol needs. In the context of the COVID-19 pandemic, physicians should be alerted to this treatment issue.

Patients should be on the replacement treatment that can better mimic physiologic plasma cortisol concentrations and proper spacing of the doubled dose of glucocorticoids should be achieved [87]. The primary aim of treatment must be not to leave the patients deficient in cortisol while combating the high inflammatory cytokine load caused by SARS-CoV-2. To avoid a possible increase in morbidity and mortality due to an insufficient compensatory selfadjusted rise in the hydrocortisone dose administration, in the case of suspected COVID-19, the "sick days" rule should be applied as early as even minor symptoms may appear [87]. This means, in the first instance, at least to double the usual doses of glucocorticoid replacement, to avoid adrenal crisis and then tailored to the stress condition. Additionally, patient information must be adequately strengthened in the order they maintain adequate stocks of 
hydrocortisone at home (both for oral and systemic administration), particularly in view of persisting measures of social confinement. If patients with adrenal insufficiency develop COVID-19, heparin should also be introduced due to coagulation abnormalities.

\section{Cushing's syndrome}

Patients with endogenous (Cushing disease or adrenal adenoma) but particularly those with exogenous hypercortisolism under treatment with pharmacological doses of glucocorticoids due to chronic autoimmune diseases as well as other inflammatory diseases [91] have also been hypothesized to be at increased risk of COVID-19 due to the immunosuppressive steroid action. Moreover, in patients under chronic glucocorticoid treatment, a high prevalence of adrenal insufficiency potentially impacting COVID-19 has been reported [92, 93].

Regarding the diagnosis of patients with endogenous Cushing's syndrome, when extensive differential diagnostic testing is not feasible, it should be deferred. Salivary cortisol/cortisone tests should be avoided due to the potential of viral contamination and infection of laboratory staff. Treatment of potential co-morbidities (such as hypertension and diabetes) should be optimized and medical treatment must be initiated. Any form of treatment of Cushing's syndrome can be considered, as to switch to a block and replace regime (metyrapone or ketoconazole plus glucocorticoid) in order to ease the monitoring [90]. The results of a small recently published phone interview conducted in Northern Italy reported that around 3\% of patients with Cushing's disease had confirmed COVID-19 vs. $<1 \%$ of the general population during the first wave of the pandemic, and with severe clinical presentation reported particularly in patients with active disease [94]. These latter findings seem to suggest that patients with chronic hypercortisolism may be at high risk of more serious consequences of SARS$\mathrm{CoV}-2$ infection and therefore they should follow strict prevention rules. It seems also reasonable that, if cough and/ or fever occur in patients living in an area of high pandemic spread, they could increase their steroid dose at the stress glucocorticoid replacement level. These patients should also be proactively informed about the possible risks related to their condition and counseled about sick days rules.

\section{Pituitary}

Specific involvement of the pituitary gland in the endocrine phenotype of COVID-19. was recently reported including pituitary apoplexy, hyponatremia, and possibly hypophysitis [95]. Moreover, both the diagnosis and treatment of pituitary diseases and their chronic but also potentially acute manifestations have been disrupted during the pandemic, which needs to be tackled despite the restrictions due to the emergency. Furthermore, many pituitary diseases do have diabetes, obesity, and VFs among their most frequent comorbidities which represent themselves as risk factors for severe COVID-19.

ACE2 and TMPRSS2 receptors are present in hypothalamic and/or pituitary tissue of COVID-19 patients [96] and SARS-CoV-2 genome has also been found in the hypothalamus of a postmortem brain of a patient affected with COVID-19 [55].

Recently, cases of pituitary apoplexy have been reported associated with COVID-19, and they may be an expression of the neurovascular phenotype of COVID-19 in which cerebrovascular endothelial damage may lead to progressive vascular syndrome or they also are linked to direct viral damage which can enter the brain through the olfactory nerve, or directly reach the median eminence [96]. In addition, SARSCoV-2 may affect the hypothalamus-pituitary via immunemediated hypophysitis, as reported in SARS-CoV 1 [97]. COVID-19 could also have indirect effects on the HPA axis mediated by cytokines that can produce functional hypopituitarism. In this regard, two studies have found thyroid abnormalities suggestive of central functional hypothyroidism and hypoadrenalism in COVID-19 patients [98]. As hypocortisolism and central hypothyroidism can persist in the long term on SARS-CoV-1 survivors [82], it will be interesting to monitor the long-term pituitary hormonal profile to estimate any possible pituitary linked morbidity in COVID-19 patients.

A recent online survey of clinical endocrinologists worldwide [99] reported several negative effects of the COVID-19 pandemic on acromegaly care, such as significant delay in surgical interventions as for other pituitary adenomas, and as well as major obstacles in the neuroradiological, biochemical, and clinical follow-up of their patients. Other issues pertinent to the COVID-19 pandemic reported by clinicians are the potential impact of medical treatment of acromegaly on blood glucose levels [100], as well as the modality of medical treatment administration possibly favoring self-administered injectable or oral somatostatin analogs and the need of improving remote communication principally via phone, but also with dedicated software. Furthermore, acromegaly as well as Cushing patients are at high risk of systemic co-morbidities such as diabetes mellitus, hypertension, obesity, and fractures [100-102] which may in turn negatively impact the outcomes of COVID-19 $[4,5,25]$ and therefore should be appropriately controlled in pituitary patients to prevent SARS-CoV-2 infection and severe COVID-19 outcomes [99].

SARS-CoV-2 infection heavily impacted the functioning of neurosurgical units with prioritization for urgent interventions. Unfortunately, prolonged waiting times conversely have been reported for patients with benign tumors, such as 
generally pituitary adenomas [103]. Moreover, there are risks of endonasal surgery linked to aerosolization of SARS-Cov-2 during but also following operations [104]. A recent study has evaluated the benefits vs. risks of elective endoscopic endonasal surgery in patients with functioning pituitary adenomas resistant to medical treatments [105]. If all preventive measures are followed, such as, first: COVID-19 home testing before hospitalization followed by absolute home quarantine; second: Covid-19 test the day before surgery; third: minimized operating team with two neurosurgeons, an anesthesiologist and two nurses; third: operators wearing maximal protective equipment; forth: operation room closed for the entire intervention; five: avoiding maneuvers that could cause droplet formation and six: elimination at end of surgery of disposable "contaminated equipment" in a SARS-CoV-2 positive room, thus, pituitary surgery results to be safe for both patients and operators [95].

Prevalence of moderate to mild hyponatremia (serum Na between 130 and $135 \mathrm{mMol} / \mathrm{L}$ ), has been reported in around $20-50 \%$ of hospitalized patients with COVID-19, which sometimes may even be the presenting symptom of the disease [95]. Hyponatremia is independently associated with old age, male sex, other co-morbidities, the severity of pneumonia, and negative outcomes [106].

It has been shown that at least in some cases, hyponatremia in COVID-19 may be related to inappropriate antidiuretic hormone secretion syndrome (SIADH) potentially caused by excess IL-6, which can induce the non-osmotic release of vasopressin [107].

SIADH in COVID-19 patients may also be induced by treatment with antibiotics, corticosteroids, and positive pressure ventilation. The only available recommendations for the management of hyponatremia in patients with COVID-19 have been given in a recent consensus of the Spanish Society for Endocrinology [108] in which it was underlined the need for an endocrinological assessment in patients with COVID19 and new onset of hyponatremia since also adrenal and thyroid dysfunctions may be involved.

Hyponatremia should also be avoided during the management of patients with diabetes insipidus in outpatients, since patients may have limited accessibility to blood testing [109]. This can be done by indicating once a week aquaresis by omitting one dose of vasopressin. It is also important to monitor weight and drink to thirst.

Therefore, in all hospitalized patients with COVID-19, close monitoring and adequate correction of sodium levels, if indicated, is recommended [109].

\section{Thyroid}

Thyroid dysfunction in COVID -19 can include direct destruction of the gland by the SARS-CoV-2 virus, precipitation of immune-mediated mechanisms, and sick euthyroid syndrome. SARS-CoV-1 autopsies found destruction of the follicular epithelium and of the parafollicular cells [110]. In COVID-19, several cases of atypical subacute thyroiditis, that has traditionally been associated with a viral origin, have been reported [111]. Subacute thyroiditis related to COVID-19 is usually reported to be painless and to present with thyrotoxicosis, which in some cases is followed by hypothyroidism. Patients are reportedly negative for thyroid antibodies [112]. In addition, autoimmune thyroiditis or Graves' disease can occasionally be triggered by the "cytokine storm" induced by SARS-CoV-2 infection [113]. Possible complications related to these autoimmune disorders include thyrotoxicosis, hypothyroidism, and Graves' ophtalmopathy.

The most frequent thyroid-related problem in COVID-19 care, particularly in hospitalized patients and in intensive care units, is sick euthyroidism. In SARS-CoV-1 patients, serum T3 and T4 were decreased in $94 \%$ and $46 \%$ of patients in the acute phase and persisted in $90 \%$ and $38 \%$ in convalescent cases [114]. These alterations were transient and resolved during follow-up. In COVID-19, low to normal T3, T4, and TSH without clinically apparent hypothyroidism have also been reported [115]. Long-term follow-up studies on thyroid function are still needed.

\section{Recommendations for people with thyroid disorders regarding COVID-19}

Regarding management of Graves' disease during COVID-19, several medical societies have recommended to take special care to patients with hyperthyroidism receiving antithyroid drugs, because symptoms of the rare side effect of agranulocytosis can overlap with COVID-19. In the resource-limited primary care setting a "block and replace" therapy for the treatment of thyrotoxicosis has been proposed [116].

Diagnostic work-up of thyroid nodules, as well as thyroid surgery for either benign or malignant thyroid nodules for differentiated thyroid cancers, have been generally postponed during the COVID-19 pandemic [117] -although individualized choices based on accurate risk profile analysis are recommended, such as prioritizing aggressive thyroid cancer cases and deferring less aggressive ones.

\section{Sex hormones and COVID-19}

Epidemiological evidence suggests similar susceptibility to SARS-CoV-2 in men and women. However, COVID-19 disease severity and mortality are higher in men [12]. A meta-analysis of over 3.1 million global cases reported odds ratios of 2.8 and 1.4 for ICU admission and death in men compared to women [118]. Similarly, a recent 
nationwide analysis of 84,000 patients and 434,000 controls in Sweden found that male sex was associated with a 1.6-fold increased risk for non-ICU hospitalization, a threefold increased risk of ICU admission, and 1.7-fold increased risk of mortality after adjustment for confounding factors [119]. Given the disparities of clinical outcomes between men and women, the impact of biological sex on immune response against COVID-19 infection has become an area of interest.

Clinical data suggest that behavioral differences might play a role in the outcome of COVID-19. Higher rates of smoking [120], various social factors including the compliance to protective measures [121] could contribute to the increased risk of severe disease in men, as well as a higher number of co-morbid diseases [122] and a low likelihood to be treated with vitamin $\mathrm{D}$ for osteoporosis [123].

Physiological mechanisms that are likely to play a role in sexual dimorphism of COVID-19 outcome include the entrance of virus to the body and immunological differences. SARS-CoV-2 uses ACE2 and the cell surface TMPRSS2 to enter the cells. Recently, it has been shown that androgens regulate transcription of these two host entry factors of SARS-CoV-2 in lung epithelial cells partly explaining the clinical observation of higher COVID-19 morbidity and mortality in men [124]. Furthermore, ACE2 is widely distributed throughout the body and higher expression and activity is related to severe COVID-19 [125]. Sex-based differences and regulation of ACE2 in various organs might contribute to different clinical manifestations in men and women.

Women and men differ in their immune response to infection [126]. A recent human study has reported that male patients had higher plasma levels of innate immune cytokines along with more robust induction of nonclassical monocytes. Female patients have significantly more robust T-cell activation than male patients during SARS-CoV-2 infection, which was sustained in old age. A poor T-cell response negatively correlates with patients' age and is associated with worse disease outcome in male patients, but not in female patients. Conversely, higher innate immune cytokines in female patients have been associated with worse disease progression, but not in male patients [127]. Overall, immune responses against SARS-CoV-2 appear to differ between men and women.

Data from the dermatologic literature suggest that bald men are more prone to COVID-19 [128] as well as that androgenetic alopecia is frequent also in women with COVID-19 [129]. However, one of the more impactful observations in this field came from patients with prostate cancer. In fact, those patients under androgen deprivation therapy [130] demonstrated in some studies to be less vulnerable to SARS-CoV-2 infection, as compared to patients who were not androgen deprived [131]. Most intriguingly, recent double-blind placebo-controlled trials showed that selective androgen receptor modulators accelerates viral clearance and reduce time to clinical remission in male patients without prostate cancer hospitalized with mild to moderate COVID-19 as well as a novel androgen receptor inhibitor did show similar positive effects in both males and females with COVID-19 [132, 133].

Therefore, a note of caution appears reasonable concerning the use of testosterone particularly in the elderly with the so-called late-onset hypogonadism in whom the usefulness of androgen replacement is still debated [134].

\section{COVID-19 vaccination and endocrine patients}

Since the opportunity of COVID-19 vaccination in some patients with endocrine diseases such as autoimmune thyroiditis has been questioned, the ESE recently released an ad hoc statement [135]. In fact, the approval of the first two vaccines in Europe by the EMA and in the US by the FDA was based on clinical trials on more than 40,000 and 30,000 subjects, respectively. The age of participants ranged from 16 to over 75 years. Patients with stable diabetes and obesity were enrolled in these trials and similar efficacy and safety were reported as compared to healthy subjects $[136,137]$. Consequently, the ESE statement supported the recommendation that COVID-19 vaccination should not be handled differently in patients with stable endocrine diseases such as autoimmune thyroiditis, Grave's disease, Addison's disease, pituitary adenomas, diabetes type 1 and 2 and obesity as compared to the general population. The ESE statement recommends to inform patients with adrenal insufficiency in case of side effects such as fever [135].

In this regard, a recent survey of more than 100 members was conducted by the Pituitary Society [138] in order to gain insights on the type of management of glucocorticoid treatment that was planned in patients with adrenal insufficiency undergoing vaccination. Interestingly, around onethird of respondents planned to automatically increase glucocorticoid dose particularly on the day of first vaccine administration but some also prior to vaccination. The majority of respondents were oriented to increase glucocorticoid dose in case of fever after vaccination, but many also in case of myalgias and arthralgias which have been reported among side effects of the vaccine. Results of this survey need to be interpreted in the frame of "expert" opinions and not of evidence based recommendation which will be based on data from the field, which we recommend to collect in an international database. 


\section{Conclusions}

\section{An updated (3) ESE "decalog" for the correct management of the endocrine phenotype of the COVID-19 pandemic}

1. We urge for vaccination against COVID-19 all health professionals, including endocrinologists particularly if relocated to COVID-19 care.

2. No emerging contraindications against COVID-19 vaccination are reported for endocrine patients. Therefore, we urge to consider for high priority vaccinations for people with diabetes and severe obesity.

3. Patients with hypoadrenalism must be carefully monitored after vaccination since an adjustment of their glucocorticoid dosing may be needed in case of systemic side effects.

4. Telemedicine and teleconsultation must be continued and implemented during the pandemic.

5. We recommend all persons with diabetes strictly control blood glucose and arterial pressure, particularly if hypertensive on medications.

6. Patients with diabetes and obesity must follow carefully all recommended protective and preventive measures and must be referred for management in case of suspected SARS-CoV-2 infection.

7. Blood glucose must be monitored carefully also in previously non-diabetic persons admitted to the hospital for COVID-19.

8. Nutritional care must be implemented for improving weight control in obesity and avoid undernourishment.

9. Hypovitaminosis D must be prevented and treated particularly in the elderly population.

10. Serum calcium and thoracic X-rays must be checked at hospital admission in all COVID-19 patients and particularly in patients with hypoparathyroidism for signs and symptoms of hypocalcemia and morphometric VFs.

\section{Compliance with ethical standards}

Conflict of interest The authors declare no competing interests.

Publisher's note Springer Nature remains neutral with regard to jurisdictional claims in published maps and institutional affiliations.

\section{References}

1. A. Gupta et al., Extrapulmonary manifestations of COVID-19. Nat. Med. 26(7), 1017-1032 (2020).

2. J. Lan et al. Structure of the SARS-CoV-2 spike receptor-binding domain bound to the ACE2 receptor. Nature 581, 215-220 (2020)
3. M. Ackermann et al. pulmonary vascular endothelialitis, thrombosis, and angiogenesis in Covid-19. N. Engl. J. Med. (2020) https://doi.org/10.1056/NEJMoa2015432

4. M. Puig-Domingo, M. Marazuela, A. Giustina, COVID-19 and endocrine diseases. A statement from the european society of endocrinology. Endocrine 68(1), 2-5 (2020).

5. M. Marazuela, A. Giustina, M. Puig-Domingo, Endocrine and metabolic aspects of the COVID-19 pandemic. Rev. Endocr. Metab. Disord. 21(4), 495-507 (2020).

6. Z. Wu, J. M. McGoogan, Characteristics of and important lessons from the coronavirus disease 2019 (COVID-19) outbreak in China: summary of a report of 72314 cases from the Chinese Center for Disease Control and Prevention. JAMA (2020). https://doi.org/10.1001/jama.2020.2648

7. S. Q. Deng, H. J. Peng, Characteristics of and public health responses to the coronavirus disease 2019 outbreak in China. J. Clin. Med. 9 (2020). https://doi.org/10.3390/jcm9020575

8. C. Alves, J. Casqueiro, J. Casqueiro, Infections in patients with diabetes mellitus: a review of pathogenesis. Indian J. Endocrinol. Metab. 16, 27 (2012).

9. J. J. Zhang, X. Dong, Y. Y. Cao, Y. D. Yuan, Y. B. Yang, Y. Q. Yan, C.A. Akdis, Y. D. Gao. Clinical characteristics of 140 patients infected with SARS-CoV-2 in Wuhan, China. Allergy (2020) https://doi.org/10.1111/all.14238

10. D. Wang, B. Hu, C. Hu, F. Zhu, X. Liu, J. Zhang, B. Wang, H. Xiang, Z. Cheng, Y. Xiong, Y. Zhao, Y. Li, X. Wang, Z. Peng, Clinical characteristics of 138 hospitalized patients with 2019 novel coronavirus-infected pneumonia in Wuhan, China. JAMA (2020). https://doi.org/10.1001/jama.2020.1585

11. M. A. Hill, C. Mantzoros, J. R. Sowers, Commentary: COVID19 in patients with diabetes. Metab. Clin. Exp. 154217 (2020). https://doi.org/10.1016/j.metabol.2020.154217

12. M.L. Brandi, A. Giustina, Sexual dimorphism of coronavirus 19 morbidity and lethality. Trends Endocrinol. Metab. 31(12), 918-927 (2020).

13. G. Corona, A. Pizzocaro, W. Vena, G. Rastrelli, F. Semeraro, A.M. Isidori, R. Pivonello, A. Salonia, A. Sforza, M. Maggi, Diabetes is most important cause for mortality in COVID-19 hospitalized patients: Systematic review and meta-analysis. Rev Endocr Metab Disord 22(2), 275-296 (2021). https://doi.org/10. 1007/s11154-021-09630-8

14. D. Prieto-Alhambra, E. Balló, E. Coma, N. Mora, M. Aragón, A. Prats-Uribe, F. Fina, M. Benítez, C. Guiriguet, M. Fàbregas, M. Medina-Peralta, T. Duarte-Salles, Filling the gaps in the characterization of the clinical management of COVID-19: 30day hospital admission and fatality rates in a cohort of 118150 cases diagnosed in outpatient settings in Spain. Int. J. Epidemiol. 49(6), 1930-1939 (2021). https://doi.org/10.1093/ije/dyaa190

15. W.-J. Guan, Z.-Y. Ni, Y. Hu et al. Clinical characteristics of coronavirus disease 2019 in China. N. Engl. J. Med. 382, 1708-20 (2020)

16. E. Burn, S.C. You, A. Sena et al. Deep phenotyping of 34,128 patients hospitalized with COVID-19 and a comparison with 81,596 influenza patients in America, Europe and Asia: an international network study. Nat. Commun. 11, 5009 (2020)

17. J.M. Casas-Rojo, J.M. Antón-Santos, J. Millán-Núñez-Cortés, C. Lumbreras-Bermejo, J.M. Ramos-Rincón, E. Roy-Vallejo, A. Artero-Mora, F. Arnalich-Fernández, J.M. García-Bruñén, J.A. Vargas-Núñez, S.J. Freire-Castro, L. Manzano-Espinosa, I. Perales-Fraile, A. Crestelo-Viéitez, F. Puchades-Gimeno, E. RodillaSala, M.N. Solís-Marquínez, D. Bonet-Tur, M.P. Fidalgo-Moreno, E.M. Fonseca-Aizpuru, F.J. Carrasco-Sánchez, E. Rabadán-Pejenaute, M. Rubio-Rivas, J.D. Torres-Peña, R. Gómez-Huelgas, en nombre del Grupo SEMI-COVID-19 Network. Clinical characteristics of patients hospitalized with COVID-19 in Spain: 
results from the SEMI-COVID-19 Registry. Rev. Clin. Esp. 220 (8), 480-494 (2020). https://doi.org/10.1016/j.rce.2020.07.003

18. H. Lee, J. R. Lee, H. Jung, J. Y. Lee, Power of universal health coverage in the era of COVID-19: a nationwide observational study. Lancet Reg. Health West. Pac. 100088 (2021). https://doi. org/10.1016/j.lanwpc.2020.100088

19. N. Holman, P. Knighton, P. Kar, J. O’Keefe, M. Curley, A. Weaver, E. Barron, C. Bakhai, K. Khunti, N.J. Wareham, N. Sattar, B. Young, J. Valabhji, Risk factors for COVID-19-related mortality in people with type 1 and type 2 diabetes in England: a population-based cohort study. Lancet Diabetes Endocrinol. 8(10), 823-833 (2020). https://doi.org/10.1016/S2213-8587(20)30271-0

20. B. Bode, V. Garrett, J. Messler et al. Glycemic characteristics and clinical outcomes of COVID-19 patients hospitalized in the United States. J. Diabetes Sci. Technol. 14, 813-22 (2020)

21. L. Zhu, Z.G. She, X. Cheng, J.J. Qin, X.J. Zhang, J. Cai, F. Lei, H. Wang, J. Xie, W. Wang, H. Li, P. Zhang, X. Song, X. Chen, M. Xiang, C. Zhang, L. Bai, D. Xiang, M.M. Chen, Y. Liu, Y. Yan, M. Liu, W. Mao, J. Zou, L. Liu, G. Chen, P. Luo, B. Xiao, C. Zhang, Z. Zhang, Z. Lu, J. Wang, H. Lu, X. Xia, D. Wang, X. Liao, G. Peng, P. Ye, J. Yang, Y. Yuan, X. Huang, J. Guo, B.H. Zhang, H. Li, Association of blood glucose control and outcomes in patients with COVID-19 and pre-existing type 2 diabetes. Cell Metab. 31(6), 1068-1077.e3 (2020). https://doi.org/10.1016/j. cmet.2020.04.021

22. M. Wargny, L. Potier, P. Gourdy, M. Pichelin, C. Amadou, P.Y. Benhamou, J.B. Bonnet, L. Bordier, O. Bourron, C. Chaumeil, N. Chevalier, P. Darmon, B. Delenne, D. Demarsy, M. Dumas, O. Dupuy, A. Flaus-Furmaniuk, J.F. Gautier, A.M. Guedj, N. Jeandidier, E. Larger, J.P. Le Berre, M. Lungo, N. Montanier, P. Moulin, F. Plat, V. Rigalleau, R. Robert, D. Seret-Bégué, P. Sérusclat, S. Smati, J.F. Thébaut, B. Tramunt, C. Vatier, F.L. Velayoudom, B. Vergès, P. Winiszewski, A. Zabulon, P.A. Gourraud, R. Roussel, B. Cariou, S. Hadjadj, CORONADO investigators. Predictors of hospital discharge and mortality in patients with diabetes and COVID-19: updated results from the nationwide CORONADO study. Diabetologia 64(4), 778-794 (2021). https://doi.org/10.1007/s00125-020-05351-w

23. L. Masana, E. Correig, C. Rodríguez-Borjabad, E. Anoro, J. A. Arroyo, C. Jericó, A. Pedragosa, M. Miret, S. Näf, A. Pardo, V. Perea, R. Pérez-Bernalte, N. Plana, R. Ramírez-Montesinos, M. Royuela, C. Soler, M. Urquizu-Padilla, A. Zamora, J. PedroBotet, Group OBOTSR. EFFECT oF STATIN THERAPY oN SARS-CoV-2 INFECTION-RELATED. Eur. Heart J. Cardiovasc. Pharmacother. pvaa128 (2020). https://doi.org/10.1093/ ehjcvp/pvaa128

24. S.B. Solerte, F. D'Addio, R. Trevisan, E. Lovati, A. Rossi, I. Pastore, M. Dell'Acqua, E. Ippolito, C. Scaranna, R. Bellante, S. Galliani, A.R. Dodesini, G. Lepore, F. Geni, R.M. Fiorina, E. Catena, A. Corsico, R. Colombo, M. Mirani, C. De Riva, S.E. Oleandri, R. Abdi, J.V. Bonventre, S. Rusconi, F. Folli, A. Di Sabatino, G. Zuccotti, M. Galli, P. Fiorina, Sitagliptin treatment at the time of hospitalization was associated with reduced mortality in patients with type 2 diabetes and COVID-19: a multicenter, case-control, retrospective, observational study. Diabetes Care $\mathbf{4 3}$ (12), 2999-3006 (2020). https://doi.org/10.2337/dc20-1521

25. J. Chávez-Reyes, C.E. Escárcega-González, E. Chavira-Suárez, A. León-Buitimea, P. Vázquez-León, J.R. Morones-Ramírez, C. M. Villalón, A. Quintanar-Stephano, B.A. Marichal-Cancino, Susceptibility for some infectious diseases in patients with diabetes: the key role of glycemia. Front Public Health 9, 559595 (2021). https://doi.org/10.3389/fpubh.2021.559595

26. B.J. Philips, J.X. Meguer, J. Redman, E.H. Baker, Factors determining the appearance of glucose in upper and lower respiratory tract secretions. Intensive Care Med. 29, 2204-2210 (2003). https://doi.org/10.1007/s00134-003-1961-2
27. A. Lecube, M. García-Ramírez, X. Muñoz, E. Sánchez, A. Seminario, M. Hernández, A. Ciudin, L. Gutiérrez, C. Hernández, R. Simó, Serum surfactant protein D as a biomarker for measuring lung involvement in obese patients with type 2 diabetes. J. Clin. Endocrinol. Metab. 102, 4109-4116 (2017). https://doi.org/10.1210/jc.2017-00913

28. A. Lecube, R. Simó, M. Pallayova, N.M. Punjabi, C. LópezCano, C. Turino, C. Hernández, F. Barbé, Pulmonary function and sleep breathing: two new targets for type 2 diabetes care. Endocr. Rev. 38, 550-573 (2017). https://doi.org/10.1210/er. 2017-00173

29. W. Guo, M. Li, Y. Dong, H. Zhou, Z. Zhang, C. Tian, R. Qin, H. Wang, Y. Shen, K. Du, L. Zhao, H. Fan, S. Luo, D. Hu, Diabetes is a risk factor for the progression and prognosis of COVID-19. Diabetes Metab. Res. Rev. e3319 (2020). https://doi.org/10. 1002/dmrr.3319

30. L. Chen, W. Sun, Y. Liu, L. Zhang, Y. Lv, Q. Wang, D. Long, Y. Wang, S. Zhao, S. Rong, L. Yu, L. Liu, Association of earlyphase in-hospital glycemic fluctuation with mortality in adult patients with coronavirus disease 2019. Diabetes Care. (2021). https://doi.org/10.2337/dc20-0780

31. R. Ghany, A. Palacio, E. Dawkins, G. Chen, D. McCarter, E. Forbes, B. Chung, L. Tamariz, Metformin is associated with lower hospitalizations, mortality and severe coronavirus infection among elderly medicare minority patients in 8 states in USA. Diabetes Metab. Syndr. 15(2), 513-518 (2021). https://doi. org/10.1016/j.dsx.2021.02.022

32. F. Rubino, S.A. Amiel, P. Zimmet, G. Alberti, S. Bornstein, R. H. Eckel, G. Mingrone, B. Boehm, M.E. Cooper, Z. Chai, S. Del Prato, L. Ji, D. Hopkins, W.H. Herman, K. Khunti, J.C. Mbanya, E. Renard, New-onset diabetes in Covid-19. N. Engl. J. Med. 383(8), 789-790 (2020). https://doi.org/10.1056/ NEJMc2018688

33. M. Apicella, M.C. Campopiano, M. Mantuano, L. Mazoni, A. Coppelli, S. Del Prato, COVID-19 in people with diabetes: understanding the reasons for worse outcomes. Lancet Diabetes Endocrinol. 8(9), 782-792 (2020). https://doi.org/10.1016/ S2213-8587(20)30238-2

34. B. Cariou, S. Hadjadj, M. Wargny, M. Pichelin, A. Al-Salameh, I. Allix et al. Phenotypic characteristics and prognosis of inpatients with COVID-19 and diabetes: the CORONADO study. Diabetologia 63, 1500-1515 (2020)

35. A. Corcillo, S. Cohen, A. Li, J. Crane, D. Kariyawasam, J. Karalliedde, Diabetic retinopathy is independently associated with increased risk of intubation: a single centre cohort study of patients with diabetes hospitalised with COVID-19. Diabetes Res. Clin. Pract. 108529 (2020). https://doi.org/10.1016/j.dia bres.2020.108529

36. R.J. Vitale, Y.K. Valtis, M.E. McDonnell, N.E. Palermo, N.D.L. Fisher, Euglycemic Diabetic Ketoacidosis With COVID-19 Infection in Patients With Type 2 Diabetes Taking SGLT2 Inhibitors. AACE Clin Case Rep. 7(1), 10-13 (2021). https://doi. org/10.1016/j.aace.2020.11.019

37. E. Burn, C. Tebé, S. Fernandez-Bertolin, M. Aragon, M. Recalde, E. Roel, A. Prats-Uribe, D. Prieto-Alhambra, T. DuarteSalles, The natural history of symptomatic COVID-19 during the first wave in Catalonia. Nat. Commun. 12(1), 777 (2021). https:// doi.org/10.1038/s41467-021-21100-y

38. N. Helvaci, N.D. Eyupoglu, E. Karabulut, B.O. Yildiz, Prevalence of obesity and its impact on outcome in patients with COVID-19: a systematic review and meta-analysis. Front. Endocrinol. 12, 598249 (2021). https://doi.org/10.3389/fendo. 2021.598249

39. M. O'Hearn, J. Liu, F. Cudhea, R. Micha, D. Mozaffarian, Coronavirus disease 2019 hospitalizations attributable to cardiometabolic conditions in the United States: a comparative risk 
assessment analysis. J. Am. Heart Assoc. 10, e019259 (2021). https://doi.org/10.1161/JAHA.120.019259

40. N.S. Hendren, J.A. de Lemos, C. Ayers, S.R. Das, A. Rao, S. Carter, A. Rosenblatt, J. Walchok, W. Omar, R. Khera, A.A. Hegde, M.H. Drazner, I.J. Neeland, J.L. Grodin, Association of body mass index and age with morbidity and mortality in patients hospitalized with COVID-19: results from the American Heart Association COVID-19 cardiovascular disease registry. Circulation 143(2), 135-144 (2021). https://doi.org/10.1161/ CIRCULATIONAHA.120.051936

41. S.A.E. Peters, S. MacMahon, M. Woodward, Obesity as a risk factor for COVID-19 mortality in women and men in the UK biobank: comparisons with influenza/pneumonia and coronary heart disease. Diabetes Obes. Metab. 23(1), 258-262 (2021). https://doi.org/10.1111/dom.14199

42. G.N. Ioannou, E. Locke, P. Green, K. Berry, A.M. O'Hare, J.A. Shah, K. Crothers, M.C. Eastment, J.A. Dominitz, V.S. Fan, Risk factors for hospitalization, mechanical ventilation, or death among 10131 US veterans with SARS-CoV-2 infection. JAMA Netw. Open 3(9), e2022310 (2020). https://doi.org/10.1001/jama networkopen.2020.22310

43. M. Wolf, J. Alladina, A. Navarrete-Welton, B. Shoults, K. Brait, D. Ziehr, A. Malhotra, C. C. Hardin, K. A. Hibbert, Obesity and critical illness in COVID-19: respiratory pathophysiology. Obesity (Silver Spring) (2021). https://doi.org/10.1002/oby.23142

44. G. Halasz, M. L. Leoni, G. Q. Villani, M. Nolli, M. Villani, Obesity, overweight and survival in critically ill patients with SARS-CoV-2 pneumonia: is there an obesity paradox? Preliminary results from Italy. Eur. J. Prev. Cardiol. 2047487320939675 (2020). https://doi.org/10.1177/2047487320939675

45. A.R. Bourgonje, A.E. Abdulle, W. Timens, J.L. Hillebrands, G.J. Navis, S.J. Gordijn, M.C. Bolling, G. Dijkstra, A.A. Voors, A.D. Osterhaus, P.H. van der Voort, D.J. Mulder, H. van Goor, Angiotensin-converting enzyme 2 (ACE2), SARS-CoV-2 and the pathophysiology of coronavirus disease 2019 (COVID-19). J. Pathol. 251(3), 228-248 (2020). https://doi.org/10.1002/path.5471

46. D. Moriconi, S. Masi, E. Rebelos, A. Virdis, M.L. Manca, S. De Marco, S. Taddei, M. Nannipieri, Obesity prolongs the hospital stay in patients affected by COVID-19, and may impact on SARS-COV-2 shedding. Obes. Res. Clin. Pract. 14(3), 205-209 (2020). https://doi.org/10.1016/j.orcp.2020.05.009

47. T. Kimura, H. Namkoong, Susceptibility of the obese population to COVID-19. Int J. Infect. Dis. 101, 380-381 (2020). https:// doi.org/10.1016/j.ijid.2020.10.015

48. R. Barazzoni, S.C. Bischoff, J. Breda, K. Wickramasinghe, Z. Krznaric, D. Nitzan et al. ESPEN expert statements and practical guidance for nutritional management of individuals with SARSCoV-2 infection. Clin. Nutr. 39(6), 1631-8 (2020)

49. M.D. Ballesteros Pomar, I. Bretón Lesmes, Clinical Nutrition in times of COVID-19. Endocrinol. Diabetes Nutr. 67(7), 427-430 (2020)

50. F. Gomes, P. Schuetz, L. Bounoure, P. Austin, M. BallesterosPomar, T. Cederholm et al. ESPEN guidelines on nutritional support for polymorbid internal medicine patients. Clin. Nutr. Edinb. Scotl. 37(1), 336-53 (2018)

51. D. Volkert, A.M. Beck, T. Cederholm, A. Cruz-Jentoft, S. Goisser, L. Hooper et al. ESPEN guideline on clinical nutrition and hydration in geriatrics. Clin. Nutr. Edinb. Scotl. 38(1), 10-47 (2019)

52. T. Li, Y. Zhang, C. Gong, J. Wang, B. Liu, L. Shi et al. Prevalence of malnutrition and analysis of related factors in elderly patients with COVID-19 in Wuhan, China. Eur. J. Clin. Nutr. 74 (6), 871-5 (2020)

53. G. Liu, S. Zhang, Z. Mao, W. Wang, H. Hu, Clinical significance of nutritional risk screening for older adult patients with COVID19. Eur. J. Clin. Nutr. 74(6), 876-83 (2020)
54. A. Ramos, C. Joaquín, M. Ros, M. Martín, M. Cachero, M. Sospedra, E. Martínez, M.J. Sendrós, J.M. Sánchez-Migallón, M. Puig-Domingo, Nutritional support in COVID -19 patients $60^{\text {th }}$ Congress of the Spanish Society of Endocrinology and Nutrition 2021 (Oral Communication)

55. S. Nampoothiri, F. Sauve, G. Ternier, D. Fernandois, C. Coelho, M. Imbernon et al. The hypothalamus as a hub for SARS-CoV-2 brain infection and pathogenesis. bioRxiv. (2020). https://doi. org/10.1101/2020.06.08.139329

56. F. Cappellini, R. Brivio, M. Casati, A. Cavallero, E. Contro, P. Brambilla, Low levels of total and ionized calcium in blood of COVID-19 patients. Clin Chem Lab Med. 58(9), e171-e173 (2020). https://doi.org/10.1515/cclm-2020-0611

57. L. Di Filippo, A.M. Formenti, P. Rovere-Querini et al. Hypocalcemia is highly prevalent and predicts hospitalization in patients with COVID-19. Endocrine 68(3), 475-478 (2020)

58. L. di Filippo, A. M. Formenti, M. Doga, S. Frara, P. RovereQuerini, E. Bosi, M. Carlucci, A. Giustina, Hypocalcemia is a distinctive biochemical feature of hospitalized COVID-19 patients. Endocrine 1-5 (2020). https://doi.org/10.1007/s12020020-02541-9

59. F. Cappellini, R. Brivio, M. Casati, A. Cavallero, E. Contro, P. Brambilla, Low levels of total and ionized calcium in blood of COVID-19 patients. Clin. Chem. Lab. Med. (2020).

60. J. Liu, P. Han, J. Wu, J. Gong, D. Tian, Prevalence and predictive value of hypocalcemia in severe COVID-19 patients. J. Infect. Public Health 13(9), 1224-1228 (2020). https://doi.org/ 10.1016/j.jiph.2020.05.029

61. J.K. Sun, W.H. Zhang, L. Zou et al. Serum calcium as a biomarker of clinical severity and prognosis in patients with coronavirus disease 2019. Aging (Albany NY) 12(12), 11287-11295 (2020). https://doi.org/10.18632/aging.103526

62. J.K. Millet et al. Physiological and molecular triggers for SARS$\mathrm{CoV}$ membrane fusion and entry into host cells. Virology 517, 3-8 (2018)

63. C.M. Booth et al. Clinical Features and Short-term Outcomes of 144 Patients With SARS in the Greater Toronto Area. JAMA 289(21), 2801-9 (2003)

64. A. Giustina, R.A. Adler, N. Binkley, R. Bouillon, P.R. Ebeling, M. Lazaretti-Castro, C. Marcocci, R. Rizzoli, C.T. Sempos, J.P. Bilezikian, Controversies in vitamin D: summary statement from an international conference. J. Clin. Endocrinol. Metab. 104, 234-240 (2019). https://doi.org/10.1210/jc.2018-01414

65. F. Tecilazich, A.M. Formenti, S. Frara, R. Giubbini, A. Giustina, Treatment of hypoparathyroidism. Best. Pract. Res. Clin. Endocrinol. Metab. 32, 955-964 (2018). https://doi.org/10.1016/j. beem.2018.12.002

66. A.M. Formenti, F. Tecilazich, S. Frara et al. Body mass index predicts resistance to active vitamin $\mathrm{D}$ in patients with hypoparathyroidism. Endocrine 66(3), 699-700 (2019)

67. A. Giustina, R. Bouillon, N. Binkley, C. Sempos, R.A. Adler, J. Bollerslev, B. Dawson-Hughes, P.R. Ebeling, D. Feldman, A. Heijboer, G. Jones, C.S. Kovacs, M. Lazaretti-Castro, P. Lips, C. Marcocci, S. Minisola, N. Napoli, R. Rizzoli, R. Scragg, J.H. White, A.M. Formenti, J.P. Bilezikian, Controversies in vitamin D: a statement from the third international conference. JBMR 4 (12), e10417 (2020). https://doi.org/10.1002/jbm4.10417

68. L.L. Benskin, A basic review of the preliminary evidence that COVID-19 risk and severity is increased in vitamin D deficiency. Front. Public Health 8, 513 (2020). https://doi.org/10.3389/ fpubh.2020.00513

69. P.B. Whittemore, COVID-19 fatalities, latitude, sunlight, and vitamin D. Am. J. Infect. Control 48(9), 1042-1044. (2020)

70. A. Giustina, R.A. Adler, N. Binkley, J. Bollerslev, R. Bouillon, B. Dawson-Hughes, P.R. Ebeling, D. Feldman, A.M. Formenti, M. Lazaretti-Castro, C. Marcocci, R. Rizzoli, C.T. Sempos, J.P. 
Bilezikian, Consensus statement from $2^{\text {nd }}$ international conference on controversies in vitamin D. Rev. Endocr. Metab. Disord. 21(1), 89-116 (2020). https://doi.org/10.1007/s11154019-09532-w

71. K.B. Christopher, Vitamin D and critical illness outcomes. Curr. Opin. Crit. Care 22(4), 332-338 (2016)

72. R. Bouillon, C. Marcocci, G. Carmeliet, D. Bikle, J.H. White, B. Dawson-Hughes, P. Lips, C.F. Munns, M. Lazaretti-Castro, A. Giustina, J. Bilezikian, Skeletal and extraskeletal actions of vitamin D: current evidence and outstanding questions. Endocr. Rev. 40, 1109-1151 (2019). https://doi.org/10.1210/er.2018-00126

73. A.R. Martineau, D.A. Jolliffe, R.L. Hooper, L. Greenberg, J.F. Aloia, P. Bergman, G. Dubnov-Raz, S. Esposito, D. Ganmaa, A. A. Ginde, E.C. Goodall, C.C. Grant, C.J. Griffiths, W. Janssens, I. Laaksi, S. Manaseki-Holland, D. Mauger, D.R. Murdoch, R. Neale, J.R. Rees, S. Simpson, I. Stelmach, G.T. Kumar, M. Urashima, C.A. Camargo, Vitamin D supplementation to prevent acute respiratory tract infections: systematic review and metaanalysis of individual participant data. BMJ (Clin. Res. Ed.) 356, i6583 (2017).https://doi.org/10.1136/bmj.i6583

74. J.P. Bilezikian, D. Bikle, M. Hewison, M. Lazaretti-Castro, A.M. Formenti, A. Gupta, M.V. Madhavan, N. Nair, V. Babalyan, N. Hutchings, N. Napoli, D. Accili, N. Binkley, D.W. Landry, A. Giustina, Mechanisms in endocrinology: vitamin D and COVID19. Eur. J. Endocrinol. 183(5), R133-R147 (2020). https://doi. org/10.1530/EJE-20-0665

75. N. Hutchings, V. Babalyan, S. Baghdasaryan, M. Qefoyan, N. Sargsyants, E. Aghajanova, A. Martirosyan, R. Harutyunyan, O. Lesnyak, A.M. Formenti, A. Giustina, J.P. Bilezikian, Patients hospitalized with COVID-19 have low levels of 25hydroxyvitamin D. Endocrine 71(2), 267-269 (2021). https:// doi.org/10.1007/s12020-020-02597-7

76. A. Giustina, Hypovitaminosis D and the endocrine phenotype of COVID-19. Endocrine. 1-11 (2021). https://doi.org/10.1007/ s12020-021-02671-8

77. D. De Smet, K. De Smet, P. Herroelen, S. Gryspeerdt, G. A. Martens, Serum 25(OH)D level on hospital admission associated with COVID-19 stage and mortality. Am. J. Clin. Pathol. aqaa252 (2020). https://doi.org/10.1093/ajcp/aqaa252

78. M. Entrenas Castillo, Entrenas, L.M. Costa, J.M. Vaquero Barrios, J.F. Alcalá Díaz, J. López Miranda, R. Bouillon, J.M. Quesada Gomez, "Effect of calcifediol treatment and best available therapy versus best available therapy on intensive care unit admission and mortality among patients hospitalized for COVID-19: a pilot randomized clinical study". J. Steroid Biochem. Mol. Biol. 203, 105751 (2020). https://doi.org/10.1016/j. jsbmb.2020.105751

79. F.M. Ulivieri, et al. Vitamin D in the COVID-19 era: a review with recommendations from A G.I.O.S.E.G expert panel. Endocrine 2021 (in press)

80. L. di Filippo, A.M. Formenti, M. Doga, E. Pedone, P. RovereQuerini, A. Giustina, Radiological Thoracic Vertebral Fractures are Highly Prevalent in COVID-19 and Predict Disease Outcomes. J. Clin. Endocrinol. Metab. 106(2), e602-e614 (2021). https://doi.org/10.1210/clinem/dgaa738

81. A.M. Formenti, E. Pedone, L. di Filippo, F.M. Ulivieri, A. Giustina, Are women with osteoporosis treated with denosumab at risk of severe COVID-19? Endocrine 70(2), 203-205 (2020). https://doi.org/10.1007/s12020-020-02500-4

82. M.K.-S. Leow, D.S.-K. Kwek, A.W.-K. Ng, K.-C. Ong, G.J.-L. Kaw, L.S.-U. Lee, Hypocortisolism in survivors of severe acute respiratory syndrome (SARS). Clin. Endocrinol. (Oxf.) 63, 197-202 (2005)

83. G. Bellastella, M.I. Maiorino, K. Esposito, Endocrine complications of COVID-19: what happens to the thyroid and adrenal glands? J. Endocrinol. Investig. 43(8), 1169-1170 (2020)
84. R. Wheatland, Molecular mimicry of ACTH in SARS-implications for corticosteroid treatment and prophylaxis. Med. Hypotheses 63, 855-62 (2004)

85. A.M. Isidori, G. Arnaldi, M. Boscaro, A. Falorni, C. Giordano, R. Giordano, R. Pivonello, R. Pofi, V. Hasenmajer, M.A. Venneri, E. Sbardella, C. Simeoli, C. Scaroni, A. Lenzi, COVID-19 infection and glucocorticoids: update from the Italian Society of Endocrinology Expert Opinion on steroid replacement in adrenal insufficiency. J. Endocrinol. Invest. 43(8), 1141-1147 (2020). https://doi.org/10.1007/s40618-020-01266-w

86. I. Bancos, J. Hazeldine, V. Chortis, P. Hampson, A.E. Taylor, J. M. Lord et al. Primary adrenal insufficiency is associated with impaired natural killer cell function: a potential link to increased mortality. Eur. J. Endocrinol. 176, 471-80 (2017)

87. W. Arlt, S.E. Baldeweg, S.H.S. Pearce, H.L. Simpson, Endocrinology in the time of COVID-19: Management of adrenal insufficiency. Eur. J. Endocrinol. 183(1), G25-G32 (2020). https://doi.org/10.1530/EJE-20-0361

88. G. Carosi, V. Morelli, G. Del Sindaco, A.L. Serban, A. Cremaschi, S. Frigerio, G. Rodari, E. Profka, R. Indirli, R. Mungari, V. Resi, E. Orsi, E. Ferrante, A. Dolci, C. Giavoli, M. Arosio, G. Mantovani, Adrenal insufficiency at the time of COVID-19: a retrospective study in patients referring to a tertiary center. J. Clin. Endocrinol. Metab. 106(3), e1354-e1361 (2021). https:// doi.org/10.1210/clinem/dgaa793

89. S. Frara, S. Chiloiro, T. Porcelli, A. Giampietro, G. Mazziotti, L. De Marinis, A. Giustina, Bone safety of dual-release hydrocortisone in patients with hypopituitarism. Endocrine 60(3), 528-531 (2018). https://doi.org/10.1007/s12020-017-1512-1

90. G. Mazziotti, A.M. Formenti, R.A. Adler, J.P. Bilezikian, A. Grossman, E. Sbardella, S. Minisola, A. Giustina, Glucocorticoid-induced osteoporosis: pathophysiological role of GH/IGF-I and PTH/VITAMIN D axes, treatment options and guidelines. Endocrine 54(3), 603-611 (2016). https://doi.org/10. 1007/s12020-016-1146-8

91. J. Newell-Price, L. Nieman, M. Reincke, A. Tabarin, Endocrinology in the time of COVID-19: management of cushing's syndrome. Eur. J. Endocrinol. (2020) https://eje.bioscientifica. com/view/journals/eje/aop/eje-20-0352/eje-20-0352.xml

92. G. Mazziotti, A.M. Formenti, S. Frara, E. Roca, P. Mortini, A. Berruti et al. MANAGEMENT OF ENDOCRINE DISEASE: Risk of overtreatment in patients with adrenal insufficiency: current and emerging aspects. Eur. J. Endocrinol. 177, R231-48 (2017)

93. C.P. Woods, N. Argese, M. Chapman, C. Boot, R. Webster, V. Dabhi et al. Adrenal suppression in patients taking inhaled glucocorticoids is highly prevalent and management can be guided by morning cortisol. Eur. J. Endocrinol. 173, 633-42 (2015)

94. A. L. Serban, E. Ferrante, G. Carosi, R. Indirli, M. Arosio, G. Mantovani, COVID-19 in Cushing disease: experience of a single tertiary centre in Lombardy. J. Endocrinol. Investig. 1-2 (2020). https://doi.org/10.1007/s40618-020-01419-x

95. S. Frara, A. Allora, L. Castellino, L. di Filippo, P. Loli, A. Giustina, Covid-19 and the pituitary. Pituitary. (2021) (submitted). https://doi.org/10.1007/s11102-021-01148-1

96. R. Pal, M. Banerjee, COVID-19 and the endocrine system: exploring the unexplored. J. Endocrinol. Investig. 43(7), 1027-1031 (2020). https://doi.org/10.1007/s40618-020-01276-8

97. S. Chiloiro, E.D. Capoluongo, T. Tartaglione et al. The changing clinical spectrum of hypophysitis. Trends Endocrinol. Metab. 30 (9), 590-602 (2019). https://doi.org/10.1016/j.tem.2019.06.004

98. W. Wang, X. Su, Y. Ding, W. Fan, J. Su, Z. Chen et al. Thyroid function abnormalities in COVID-19 patients. medRxiv. (2020). https://doi.org/10.1101/2020.06.15.20130807

99. A. Giustina, E. Legg, B.M. Cesana, S. Frara, P. Mortini, M. Fleseriu, Results from ACROCOVID: an international survey on 
the care of acromegaly during the COVID-19 era. Endocrine $\mathbf{7 1}$ (2), 273-280 (2021). https://doi.org/10.1007/s12020-020-02565-1

100. S. Frara, F. Maffezzoni, G. Mazziotti, A. Giustina, Current and emerging aspects of diabetes mellitus in acromegaly. Trends Endocrinol. Metab. 27(7), 470-483 (2016). https://doi.org/10. 1016/j.tem.2016.04.014

101. A. Giustina, A. Barkan, A. Beckers, N. Biermasz, B. M. K. Biller, C. Boguszewski, M. Bolanowski, V. Bonert, M. D. Bronstein, F. F. Casanueva, D. Clemmons, A. Colao, D. Ferone, M. Fleseriu, S. Frara, M. R. Gadelha, E. Ghigo, M. Gurnell, A. P. Heaney, K. Ho, A. Ioachimescu, L. Katznelson, F. Kelestimur, J. Kopchick, M. Krsek, S. Lamberts, M. Losa, A. Luger, P. Maffei, M. Marazuela, G. Mazziotti, M. Mercado, P. Mortini, S. Neggers, A. M. Pereira, S. Petersenn, M. Puig-Domingo, R. Salvatori, I. Shimon, C. Strasburger, S. Tsagarakis, A. J. van der Lely, J. Wass, M. C. Zatelli, S. Melmed, A consensus on the diagnosis and treatment of acromegaly comorbidities: an update. J. Clin. Endocrinol. Metab. 105(4) (2020). https://doi.org/10.1210/ clinem/dgz096

102. G. Mazziotti, A.M. Formenti, S. Frara, F. Maffezzoni, M. Doga, A. Giustina, Diabetes in cushing disease. Curr. Diabetes Rep. 17 (5), 32 (2017). https://doi.org/10.1007/s11892-017-0860-9

103. A. Giustina, Pituitary adenomas....nomen omen? Eur. J. Endocrinol. (2021 in press)

104. C. Iorio-Morin, M. Hodaie, C. Sarica, N. Dea, H.J. Westwick, S. D. Christie, P.J. McDonald, M. Labidi, J.P. Farmer, S. Brisebois, F. D'Aragon, A. Carignan, D. Fortin, Letter: the risk of COVID19 infection during neurosurgical procedures: a review of severe acute respiratory distress syndrome coronavirus 2 (SARS-CoV2) modes of transmission and proposed neurosurgery-specific measures for mitigation. Neurosurgery 87(2), E178-E185 (2020). https://doi.org/10.1093/neuros/nyaa157

105. F. Penner, S. Grottoli, M.M.R. Lanotte, D. Garbossa, F. Zenga, Pituitary surgery during Covid-19: a first hand experience and evaluation. J. Endocrinol. Investig. 44(3), 635-636 (2021). https://doi.org/10.1007/s40618-020-01354-x

106. P. Tzoulis, J. A. Waung, E. Bagkeris, Z. Hussein, A. Biddanda, J. Cousins, A. Dewsnip, K. Falayi, W. McCaughran, C. Mullins, A. Naeem, M. Nwokolo, H. Quah, S. Bitat, E. Deyab, S. Ponnampalam, P. M. Bouloux, H. Montgomery, S. E. Baldeweg, Dysnatremia is a predictor for morbidity and mortality in hospitalized patients with COVID-19. J. Clin. Endocrinol. Metab. (2021). https://doi.org/10.1210/clinem/dgab10

107. A. Berni, D. Malandrino, G. Parenti, M. Maggi, L. Poggesi, A. Peri, Hyponatremia, IL-6, and SARS-CoV-2 (COVID-19) infection: may all fit together? J. Endocrinol. Investig. 43(8), 1137-1139 (2020). https://doi.org/10.1007/s40618-020-01301-w

108. A. Fernandez Martinez, D. Barajas Galindo, J. Ruiz Sanchez, Management of hyponatraemia and hypernatraemia during the Covid-19 pandemic: a consensus statement of the Spanish Society for Endocrinology (Acqua Neuroendocrinology Group). Rev. Endocr. Metab. Disord. (2021). https://doi.org/10.1007/ s11154-021-09627-3

109. M. Christ-Crain, E.J. Hoorn, M. Sherlock, C.J. Thompson, J.A.H. Wass, ENDOCRINOLOGY IN THE TIME OF COVID-19: Management of diabetes insipidus and hyponatraemia. Eur. J. Endocrinol. 183(1), G9-G15 (2020). https://doi.org/10.1530/EJE-20-0338

110. X.H. Yao, T.Y. Li, Z.C. He et al. A pathological report of three COVID-19 cases by minimally invasive autopsies. Zhonghua Bing Li Xue Za Zhi 49, E009 (2020)

111. I. Muller, D. Cannavaro, D. Dazzi, D. Covelli, G. Mantovani, A. Muscatello, E. Ferrante, E. Orsi, V. Resi, V. Longari, M. Cuzzocrea, A. Bandera, E. Lazzaroni, A. Dolci, F. Ceriotti, T.E. Re, A. Gori, M. Arosio, M. Salvi, SARS-CoV-2-related atypical thyroiditis. Lancet Diabetes Endocrinol. 8, 739-741 (2020). https://doi.org/10.1016/S2213-8587(20)30266-7
112. A. Brancatella, D. Ricci, N. Viola, D. Sgrò, F. Santini, F. Latrofa, Subacute thyroiditis after Sars-COV-2 infection. J. Clin. Endocrinol. Metab. 105, dgaa276 (2020)

113. S. Jiménez-Blanco, B. Pla-Peris, M. Marazuela, COVID-19: a cause of recurrent Graves' hyperthyroidism? J. Endocrinol. Investig. 44(2), 387-388 (2021). https://doi.org/10.1007/s40618020-01440-0

114. W. Wang, Y.X. Ye, H. Yao, Evaluation and observation of serum thyroid hormone and parathyroid hormone in patients with severe acute respiratory syndrome. J. Chin. Antituberc. Assoc. 25, 232-234 (2003)

115. C. Huang, Y. Wang, X. Li, L. Ren, J. Zhao, Y. Hu et al. Clinical features of patients infected with 2019 novel coronavirus in Wuhan, China. Lancet 395, 497-506 (2020)

116. K. Boelaert, W.E. Visser, P.N. Taylor, C. Moran, J. Léger, L. Persani, ENDOCRINOLOGY IN THE TIME OF COVID-19: Management of hyperthyroidism and hypothyroidism. Eur. J. Endocrinol. 183(1), G33-G39 (2020). https://doi.org/10.1530/ EJE-20-0445

117. A. Vrachimis, I. Iacovou, E. Giannoula, L. Giovanella, Endocrinology in the time of COVID-19: management of thyroid nodules and cancer. Eur. J. Endocrinol. EJE-20-0269.R2 (2020). https://doi.org/10.1530/EJE-20-0269

118. H. Peckham, N.M. de Gruijter, C. Raine, A. Radziszewska, C. Ciurtin, L.R. Wedderburn, E.C. Rosser, K. Webb, C.T. Deakin, Male sex identified by global COVID-19 meta-analysis as a risk factor for death and ITU admission. Nat. Commun. 11(1), 6317 (2020). https://doi.org/10.1038/s41467-020-19741-6

119. J. Bergman, M. Ballin, A. Nordström, P. Nordström, Risk factors for COVID-19 diagnosis, hospitalization, and subsequent allcause mortality in Sweden: a nationwide study. Eur. J. Epidemiol. 1-12 (2021). https://doi.org/10.1007/s10654-021-00732-w

120. H. Agrawal, N. Das, S. Nathani, S. Saha, S. Saini, S.S. Kakar, P. Roy, An assessment on Impact of COVID-19 infection in a gender specific manner. Stem Cell Rev. Rep. 17(1), 94-112 (2021). https://doi.org/10.1007/s12015-020-10048-Z

121. M.H. Haischer, R. Beilfuss, M.R. Hart, L. Opielinski, D. Wrucke, G. Zirgaitis, T.D. Uhrich, S.K. Hunter, Who is wearing a mask? Gender-, age-, and location-related differences during the COVID-19 pandemic. PLoS ONE 15(10), e0240785 (2020). https://doi.org/10.1371/journal.pone.0240785

122. F. Mauvais-Jarvis, N. Bairey Merz, P.J. Barnes, R.D. Brinton, J. J. Carrero, D.L. DeMeo, G.J. De Vries, C.N. Epperson, R. Govindan, S.L. Klein, A. Lonardo, P.M. Maki, L.D. McCullough, V. Regitz-Zagrosek, J.G. Regensteiner, J.B. Rubin, K. Sandberg, A. Suzuki, Sex and gender: modifiers of health, disease, and medicine. Lancet 396(10250), 565-582 (2020). https:// doi.org/10.1016/S0140-6736(20)31561-0

123. P. R. Ebeling, R. A. Adler, G. Jones, U. A. Liberman, G. Mazziotti, S. Minisola, C. F. Munns, N. Napoli, A. G. Pittas, A. Giustina, J. P. Bilezikian, R. Rizzoli, MANAGEMENT OF ENDOCRINE DISEASE: Therapeutics of vitamin D. Eur. J. Endocrinol. R239-R259 (2018). https://doi.org/10.1530/EJE-18-0151

124. Y. Qiao, X.M. Wang, R. Mannan, S. Pitchiaya, Y. Zhang, J.W. Wotring, L. Xiao, D.R. Robinson, Y.M. Wu, J.C. Tien, X. Cao, S.A. Simko, I.J. Apel, P. Bawa, S. Kregel, S.P. Narayanan, G. Raskind, S.J. Ellison, A. Parolia, S. Zelenka-Wang, L. McMurry, F. Su, R. Wang, Y. Cheng, A.D. Delekta, Z. Mei, C.D. Pretto, S. Wang, R. Mehra, J.Z. Sexton, A.M. Chinnaiyan, Targeting transcriptional regulation of SARS-CoV-2 entry factors ACE2 and TMPRSS2. Proc. Natl Acad. Sci. U.S.A. 118(1), e2021450118 (2020). https://doi.org/10.1073/pnas.2021450118

125. B.G.G. Pinto, A.E.R. Oliveira, Y. Singh, L. Jimenez, A.N.A. Gonçalves, R.L.T. Ogava, R. Creighton, J.P. Schatzmann Peron, H.I. Nakaya, ACE2 expression is increased in the lungs of patients with comorbidities associated with severe COVID-19. J. 
Infect. Dis. 222(4), 556-563 (2020). https://doi.org/10.1093/ infdis/jiaa332

126. S.L. Klein, K.L. Flanagan, Sex differences in immune responses. Nat. Rev. Immunol. 16(10), 626-38 (2016). https://doi.org/10. 1038/nri.2016.90

127. T. Takahashi, M.K. Ellingson, P. Wong, B. Israelow, C. Lucas, J. Klein, J. Silva, T. Mao, J.E. Oh, M. Tokuyama, P. Lu, A. Venkataraman, A. Park, F. Liu, A. Meir, J. Sun, E.Y. Wang, A. Casanovas-Massana, A.L. Wyllie, C.B.F. Vogels, R. Earnest, S. Lapidus, I.M. Ott, A.J. Moore, Yale IMPACT Research Team, A. Shaw, J. B. Fournier, C. D. Odio, S. Farhadian, C. Dela Cruz, N. D. Grubaugh, W. L. Schulz, A. M. Ring, A. I. Ko, S. B. Omer, A. Iwasaki, Sex differences in immune responses that underlie COVID-19 disease outcomes. Nature 588 (7837), 315-320 (2020). https://doi.org/10.1038/s41586-020-2700-3

128. J. Lee, A. Yousaf, W. Fang, M.S. Kolodney, Male balding is a major risk factor for severe COVID-19. J. Am. Acad. Dermatol. 83 (5), e353-e354 (2020). https://doi.org/10.1016/j.jaad.2020.07.062

129. C.G. Wambier, S. Vaño-Galván, J. McCoy, A. Gomez-Zubiaur, S. Herrera, Á. Hermosa-Gelbard, O.M. Moreno-Arrones, N. Jiménez-Gómez, A. González-Cantero, P. Fonda-Pascual, G. Segurado-Miravalles, J. Shapiro, B. Pérez-García, A. Goren, Androgenetic alopecia present in the majority of patients hospitalized with COVID-19: The "Gabrin sign". J. Am. Acad. Dermatol. 83(2), 680-682 (2020). https://doi.org/10.1016/j.jaad. 2020.05.079

130. A.M. Formenti, A. Dalla Volta, L. di Filippo, A. Berruti, A. Giustina, Effects of medical treatment of prostate cancer on bone health. Trends Endocrinol. Metab. 32(3), 135-158 (2021). https://doi.org/10.1016/j.tem.2020.12.004

131. M. Montopoli, S. Zumerle, R. Vettor, M. Rugge, M. Zorzi, C.V. Catapano, G.M. Carbone, A. Cavalli, F. Pagano, E. Ragazzi, T. Prayer-Galetti, A. Alimonti, Androgen-deprivation therapies for prostate cancer and risk of infection by SARS-CoV-2: a population-based study ( $\mathrm{N}=4532)$. Ann. Oncol. 31(8), 1040-1045 (2020). https://doi.org/10.1016/j.annonc.2020.04.479

132. F.A. Cadegiani, J. McCoy, C. Gustavo Wambier, A. Goren, Early antiandrogen therapy with dutasteride reduces viral shedding, inflammatory responses, and time-to-remission in males with COVID-19: a randomized, double-blind, placebo-controlled interventional trial (EAT-DUTA AndroCoV Trial-Biochemical). Cureus 13(2), e13047 (2021). https://doi.org/10.7759/cureus.13047
133. F.A. Cadegiani, J. McCoy, C. Gustavo Wambier, S. Vaño-Galván, J. Shapiro, A. Tosti, R.A. Zimerman, A. Goren, Proxalutamide significantly accelerates viral clearance and reduces time to clinical remission in patients with mild to moderate COVID-19: results from a randomized, double-blinded, placebocontrolled trial. Cureus 13(2), e13492 (2021). https://doi.org/10. 7759/cureus. 13492

134. G. Valenti, S. Bossoni, A. Giustina, D. Maugeri, M. Motta, G.B. Vigna, R. Fellin, F. Corica, A. Corsonello, G. Paolisso, M. Barbagallo, L. Dominguez, L. Denti, G. Ceda, E. Ferrari, B. Pontiggia, F. Strollo, Italian Study Group on Geriatric Endocrinology. Consensus Document on substitution therapy with testosterone in hypoandrogenic elderly men. Aging Clin. Exp. Res. 14(6), 439-64 (2002). https://doi.org/10.1007/BF03327345

135. A. Luger, A. Giustina, R. Peeters, European Society of Endocrinology (ESE)'s statement concerning COVID19 vaccination: 'follow the same recommendations for patients with stable endocrine disorders as for the general population www-esehormones.org

136. F.P. Polack, S.J. Thomas, N. Kitchin, J. Absalon, A. Gurtman, S. Lockhart, J.L. Perez, G. Perez Marc, E.D. Moreira, C. Zerbini, R. Bailey, K.A. Swanson, S. Roychoudhury, K. Koury, P. Li, W.V. Kalina, D. Cooper, R.W. Frenck Jr., L.L. Hammitt, O. Tureci, H. Nell, A. Schaefer, S. Unal, D.B. Tresnan, S. Mather, P.R. Dormitzer, U. Sahin, K.U. Jansen, W.C. Gruber, C.C.T. Group, Safety and efficacy of the BNT162b2 mRNA Covid-19 vaccine. N. Engl. J. Med. 383(27), 2603-2615 (2020). https://doi.org/10. 1056/NEJMoa2034577

137. L.R. Baden, H.M. El Sahly, B. Essink, K. Kotloff, S. Frey, R. Novak, D. Diemert, S.A. Spector, N. Rouphael, C.B. Creech, J. McGettigan, S. Khetan, N. Segall, J. Solis, A. Brosz, C. Fierro, H. Schwartz, K. Neuzil, L. Corey, P. Gilbert, H. Janes, D. Follmann, M. Marovich, J. Mascola, L. Polakowski, J. Ledgerwood, B.S. Graham, H. Bennett, R. Pajon, C. Knightly, B. Leav, W. Deng, H. Zhou, S. Han, M. Ivarsson, J. Miller, T. Zaks, C.S. Group, Efficacy and safety of the mRNA-1273 SARS-CoV-2 vaccine. N. Engl. J. Med. 384(5), 403-416 (2021). https://doi. org/10.1056/NEJMoa2035389

138. L. Katznelson, M. Gadelha, Glucocorticoid use in patients with adrenal insufficiency following administration of the COVID-19 vaccine: a pituitary society statement. Pituitary. (2021). https:// doi.org/10.1007/s11102-021-01130-x 